\title{
Imaging techniques and histology in the evaluation of liver fibrosis in hepatosplenic schistosomiasis mansoni in Brazil: a comparative study
}

\author{
Izabela Voieta1, Leonardo C de Queiroz ${ }^{2}$, Luciene M Andrade ${ }^{1,3}$, Luciana Cristina S Silva', \\ Vitor F Fontes ${ }^{1}$, Aryon Barbosa Jr ${ }^{4}$, Vivian Resende ${ }^{5}$, Andy Petroianu ${ }^{5}$, Zilton Andrade ${ }^{4}$, \\ Carlos Mauricio Antunes ${ }^{1}$, José Roberto Lambertucci ${ }^{1 /+}$
}

\begin{abstract}
${ }^{2}$ Serviço de Radiologia, Hospital das Clínicas ${ }^{5}$ Serviço de Cirurgia de Fígado e Vias Biliares ${ }^{1}$ Programa de Pós-Graduação em Ciências da Saúde: Infectologia e Medicina Tropical, Faculdade de Medicina, Universidade Federal de Minas Gerais, Av. Alfredo Balena 190 sala 169, 30.130-100 Belo Horizonte, MG, Brasil ' ${ }^{3}$ Laboratórios Hermes Pardini,

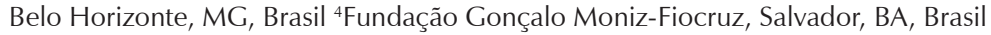

Few publications have compared ultrasound (US) to histology in diagnosing schistosomiasis-induced liver fibrosis (LF); none has used magnetic resonance (MR). The aim of this study was to evaluate schistosomal LF using these three methods. Fourteen patients with hepatosplenic schistosomiasis admitted to hospital for surgical treatment of variceal bleeding were investigated. They were submitted to upper digestive endoscopy, US, MR and wedge liver biopsy. The World Health Organization protocol for US in schistosomiasis was used. Hepatic fibrosis was classified as absent, slight, moderate or intense. Histology and MR confirmed Symmers' fibrosis in all cases. US failed to detect it in one patient. Moderate agreement was found comparing US to MR; poor agreement was found when US or MR were compared to histology. Re-classifying LF as only slight or intense created moderate agreement between imaging techniques and histology. Histomorphometry did not separate slight from intense LF. Two patients with advanced hepatosplenic schistosomiasis presented slight LF. Our data suggest that the presence of the characteristic periportal fibrosis, diagnosed by US, MR or histology, associated with a sign of portal hypertension, defines the severity of the disease. We conclude that imaging techniques are reliable to define the presence of LF but fail in grading its intensity.

Key words: schistosomiasis - ultrasound - magnetic resonance - liver fibrosis - Symmers' fibrosis - splenectomy - portal hypertension

Schistosomiasis affects 200 million people worldwide (Lambertucci 1993). Hepatosplenic schistosomiasis mansoni is a severe form of the disease and develops into periportal fibrosis and portal hypertension in nearly $10 \%$ of infected individuals (Prata 1987, Pinto-Silva et al. 1994, Lambertucci et al. 2000, Andrade 2004, Maia et al. 2007).

Abdominal ultrasound (US) is considered a simple, safe and inexpensive imaging technique in the evaluation of schistosomal liver involvement and is often used as the surrogate for the gold-standard in the diagnosis of liver fibrosis (LF) and classification of its intensity (Andrade 2005, Lambertucci et al. 2008). The sensitivity and specificity of US in the recognition of LF is comparable to histological examination of liver fragments (Cerri et al. 1984, Homeida et al. 1988a, Abdel-Wahab et al. 1989). The development of portable US devices is considered an advance in the investigation of morbidity in field-based studies (Marinho et al. 2006). US may also be used to

\footnotetext{
Financial support: $\mathrm{CNPq}$

+ Corresponding author: lamber@uai.com.br

Received 9 January 2009

Accepted 18 December 2009
}

evaluate the dynamic changes produced by portal hypertension and, accordingly, may suggest the presence of oesophageal varices (Abdel-Latif et al. 1981, Davidson et al. 1991, Abdel-Wahab et al. 1993, Richter et al. 1998). However, this diagnostic tool requires well-trained physicians and its standardization is still a matter of debate after two World Health Organization (WHO) workshops (Cairo Working Group 1992, Niamey Working Group 1996, Lambertucci et al. 2001).

Magnetic resonance (MR) is a very sensitive imaging technique that has been used to evaluate liver involvement in a variety of diseases. In schistosomiasis, MR alterations have already been described in case reports and in series of cases (Patel et al. 1993, Willemsen et al. 1995, Lambertucci et al. 2002, 2004, Silva et al. 2006, Bezerra et al. 2007, Silva 2007). However, to our knowledge, no study has compared US and MR to liver histology in patients with hepatosplenic schistosomiasis.

The aim of the present study was to compare abdominal US and MR to liver histology in the diagnosis and evaluation of Symmers' fibrosis intensity in schistosomiasis mansoni.

\section{PATIENTS, MATERIALS AND METHODS}

Patients - The study was approved by the Ethical Board of the Federal University of Minas Gerais, Brazil. 
All study subjects signed an informed consent for participation. Fourteen patients (10 males) referred to the Tropical Diseases Outpatient Clinic with a diagnosis of hepatosplenic schistosomiasis, portal hypertension and indication for surgical intervention (splenectomy and/or suturing of oesophago-gastric varices) were selected for this study. Schistosomiasis was defined by microscopic evidence of active infection (positive parasitological stool examination or eggs in rectal biopsy) and a history of contact with stream waters of an endemic area. Patients included in the study did not have other causes of chronic liver disease, such as cirrhosis, congestive heart failure or toxic or viral hepatitis. Age ranged from 20-57 years (39 \pm 10.4). Baseline characteristics are presented in Table I.

Methods - Outpatient assessment included clinical examination, abdominal US, upper digestive endoscopy, serum markers of autoimmune hepatitis, hepatitis B and $\mathrm{C}$ serology, blood cell count and liver function evaluation (serum albumin and prothrombin time). Seventeen patients fulfilled the criteria for inclusion, but three were excluded because wedge liver biopsy was not available or because of sclerosing cholangitis (Fig. 1).

US examination of the abdomen was performed using a real-time ALOKA SSD device 1700 (Japan) with electronic convex $3.5 \mathrm{MHz}$ transducer, according to the $\mathrm{WHO}$ proto-

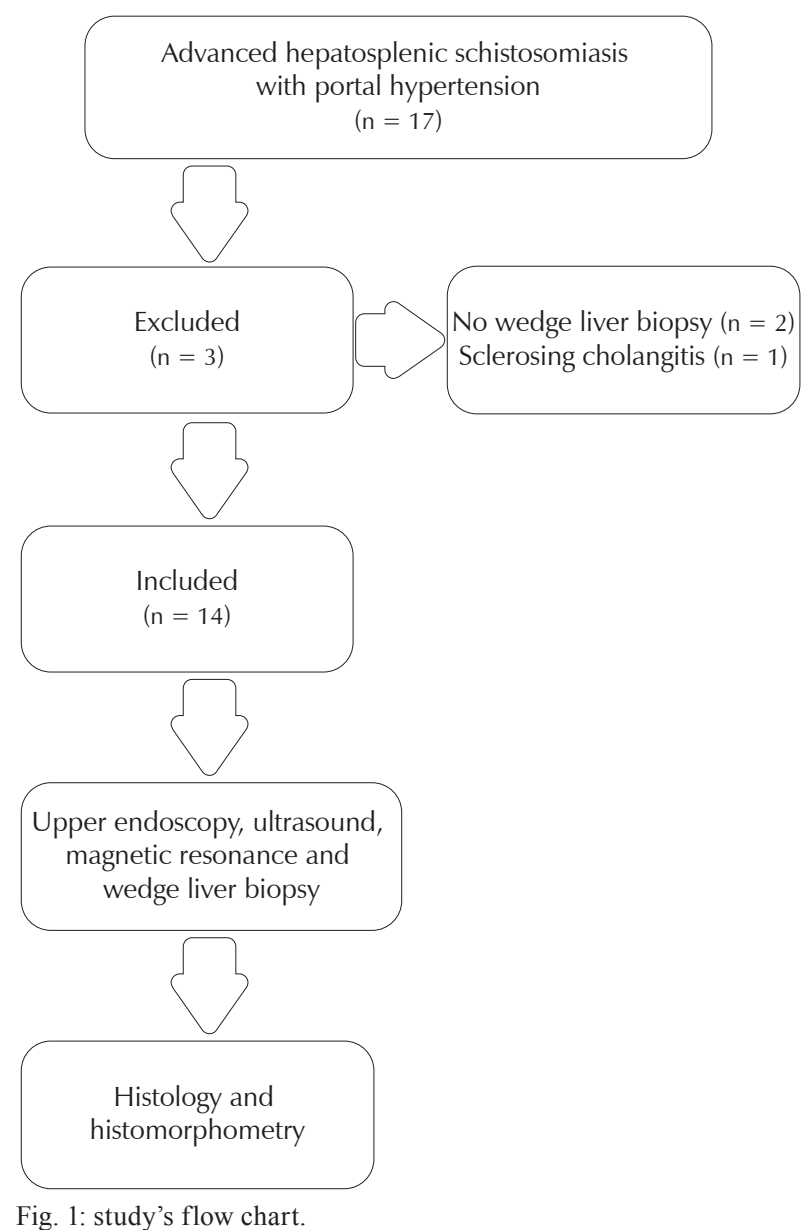

col for US assessment of schistosomiasis-related morbidity (Niamey Working Group 1996). US hepatic fibrosis was classified as absent (pattern A), slight (B, C, D and Dc), moderate $(\mathrm{E}$ and $\mathrm{Ec})$ or intense $(\mathrm{F})$. The presence of collateral vessels and the spleen length were evaluated. MR was obtained using a GE 1.5 T Sigma unit (Milwaukee, USA). Axial and coronal 7-mm-thick slices were performed in T1 and T2-weighted sequences, before and after gadopentetate dimeglumine (Gd-DTPA) administration. MR analysis was guided by an adaptation of the WHO protocol for US. US and MR were blindly performed (Fig. 2). Radiologists and pathologists knew that all patients had schistosomiasis, but they were not informed of the clinical form of the disease.

Radiology was the specialty of both observers. The US examiner had seven years of experience in radiology; he was trained to use the WHO protocol for USrelated morbidity in schistosomiasis. The MR examiner had 10 years of experience in radiology. One observer viewed the MR and other the US images. The inter-observer agreement for US has been reported to be moderate (kappa 0.45) (Doehringer et al. 1992). For MR the intra and inter-observer agreement has been shown to be substantial (kappa 0.65 and 0.66, respectively) (Bezerra et al. 2007).

Wedge liver biopsy fragments of $\sim 3 \mathrm{~cm}^{3}$ were obtained from the left liver lobe during splenectomy, fixed

\section{TABLE I}

Demographic characteristics, clinical and laboratory aspects of 14 patients with advanced hepatosplenic schistosomiasis and portal hypertension, Belo Horizonte, Minas Gerais, Brazil 2006-2007

Characteristics of subjects

$(\mathrm{n}=14)$

Data

$\begin{array}{lc}\text { Mean age in years } \pm \text { SD } & 39 \pm 10.4 \\ \text { Age range (years) } & (20-57) \\ \text { Gender } & \\ \quad \text { Male } & 10 \\ \text { Skin color } & \\ \quad \text { White } & 4 \\ \quad \text { Non white } & 10 \\ \text { Exposed to stream waters } & 14 \\ \text { Upper digestive bleeding } & 12 \\ \text { Positive parasitological stool examination } & 2 \\ \text { Previous treatment for Schistosoma mansoni } & 8 \\ \text { Hemogram } & \\ \quad \text { Leukopenia } & \\ \quad \text { Thrombocytopenia } & 11 \\ \text { Palpable liver } & 12 \\ \text { Palpable spleen } & \\ \text { Previous splenectomy } & \end{array}$

$a$ : anaemia: $\mathrm{Hb}<12 \mathrm{~g} \%$ women and $<14 \mathrm{~g} \%$ men; thrombocytopenia: platelets $<150.000 \mathrm{~mm}^{3}$; leukopenia: global leukocytes $<4.300$ cels $/ \mathrm{mm}^{3} ; b$ : two were submitted to previous splenectomy and one was obese, two subjects had only palpable spleen. 

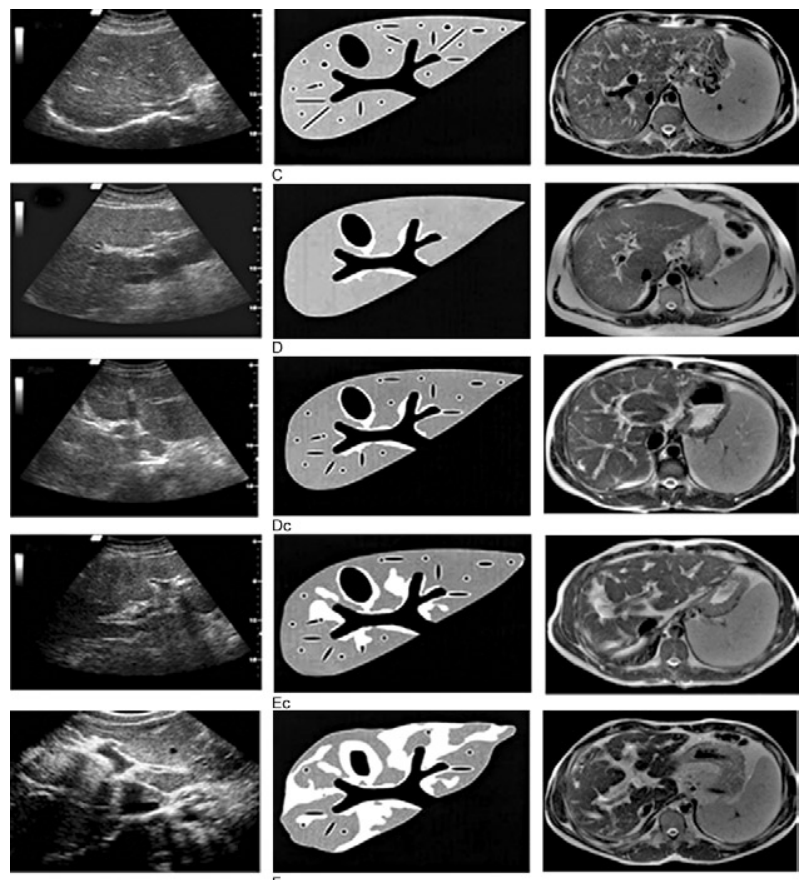

Fig. 2: World Health Organization patterns for ultrasound (US) assessment of schistosomiasis-related morbidity (middle column) (US on the left and magnetic resonance on the right).

in $10 \%$ formalin and embedded in paraffin (Fig. 3). The section preparations were stained with hematoxylin and eosin (H\&E) and were examined under light microscopy. Randomly sampled 5 - $\mu$ m-thick liver histological sections stained with picrosirius red for interstitial collagen were examined by semiautomatic morphometry using the LEICA QWIN-3.1 (Microsystem Imagina Solutions LTD, Cambridge, UK) (Fig. 4). For morphometric measurements a total sectional area of $4,296,920 \mathrm{~m} \mu^{2}$ per patient was evaluated. The sectional area of the red-stained fibrous tissue was directly measured and calculated as a percentage of the total area examined, as previously described (Barbosa 2001, Coutinho et al. 2003).
Statistical analysis - Data were stored using EpiData 3.1 software [JM Lauristen (ed.), Odense Denmark, EpiData Association, 2000-2006 (available from: http:// www.epidata.dk)]. Statistical analysis was performed using EpiInfo 3.3.2 [Centers for Disease Control and Prevention, USA, 2005 (available from: http://www.cdc.gov/ EpiInfo/epiinfo.htm)] and SPSS 12.0 for Windows (SPSS Incorporation, Chicago, Illinois, USA, 2005). Comparisons of quantitative and qualitative variables among US, MR and liver biopsy were made using Wilcoxon and McNemar tests. Agreement between image methods was evaluated by kappa index or Spearman's test. The degree of agreement for kappa was classified according to Landis and Koch (1977) (Fig. 5). Other associations between the three groups (bleeding frequency, spleen length and LF) were appraised by the nonparametric Mann-Whitney test or Fisher's exact test, as appropriate.

\section{RESULTS}

All patients had oesophageal varices confirmed by endoscopy and 12 reported some form of previous digestive bleeding. Only four patients underwent sclerotherapy of oesophageal varices. Two patients excreting Schistosoma mansoni eggs were treated with praziquantel.

In 13 out of $14(92.8 \%)$ patients, US showed the characteristic features of schistosomal liver fibrosis, whereas MR identified periportal thickening in all 14.

Patients with hepatosplenic schistosomiasis are shown in Fig. 5. Symmers' fibrosis was confirmed by histology. The white clay pipe-stem aspect was present in all cases, with variable degrees of septal fibrosis maintaining the acinar architecture of the hepatic parenchyma. Periovular granulomas were rare, small, fibrotic and sometimes with calcified ova.

During splenectomy, the liver surface presented a wide range of patterns (Fig. 6). The surface varied from smooth to pseudo-nodular with macroscopic whitish bands. Liver wedges also varied from sharp to blunt and consistency varied from soft to hard.

US, MR and histology classified hepatic fibrosis as moderate in four patients $(28.5 \%$; patients $3,4,6$ and 14). In six patients $(42.8 \%)$ the difference in the intensity of fibrosis diagnosed by the different methods was
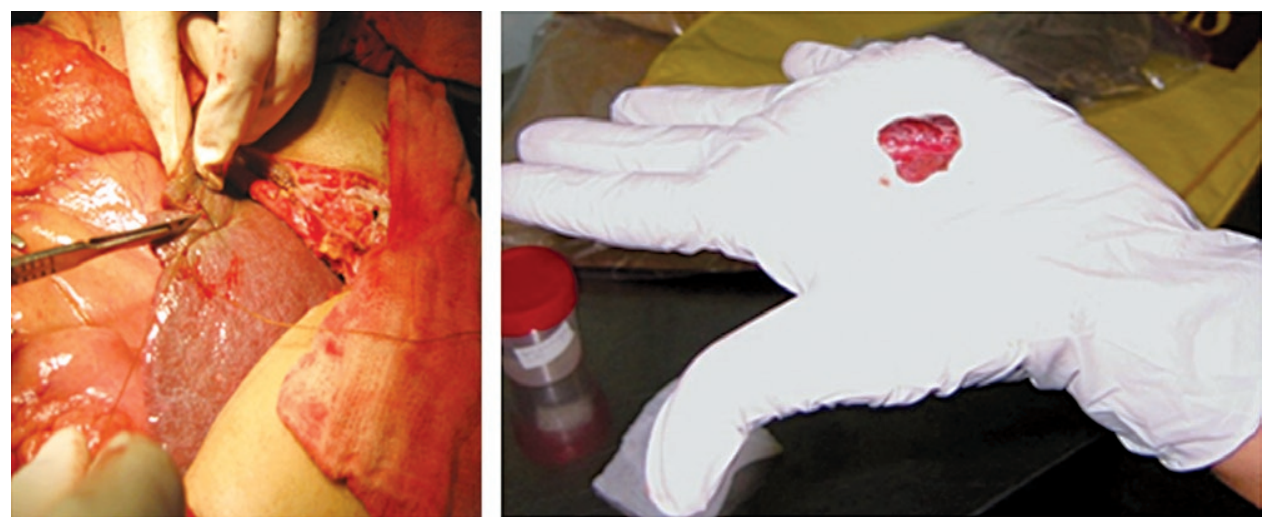

Fig. 3: wedge liver biopsy being performed during surgery on the left and a fragment of $3 \mathrm{~cm}^{3}$ on the right. 


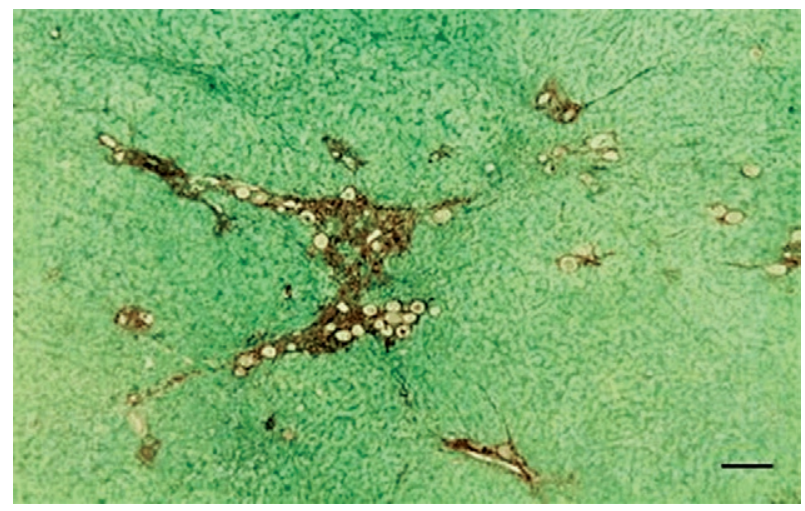

Fig. 4: liver histological slide stained with picrosirius-red for interstitial collagens.

\begin{tabular}{|lc|}
\hline Values of kappa & Interpretation \\
\hline$<0$ & No agreement \\
$0-0.19$ & Poor agreement \\
$0.20-0.39$ & Fair agreement \\
$0.40-0.59$ & Moderate agreement \\
$0.60-0.79$ & Substantial agreement \\
$0.80-1.00$ & Almost perfect agreement \\
\hline
\end{tabular}

Fig. 5: interpretation of kappa index values.

of one degree, e.g., from moderate to intense (patients $1,2,9,10,11$ and 12). The three methods completely disagreed in four patients $(28.5 \%$; patients $5,7,8$ and 13). These results are summarised in Table II. Agreement between imaging methods, as evaluated by kappa index, was 0.41 (moderate); after re-grouping grades absent and slight together (labelled slight) and grades moderate and intense together (labelled intense), substantial concordance was observed (kappa $=0.63$ ).

Agreement between US and histology was poor (kap$\mathrm{pa}=0.06)$ and remained so even after re-grouping into slight and intense (kappa $=-0.17)$. Similar results were observed comparing MR to histology. Excluding one patient (patient 7, Table II) who presented absent fibrosis in US and moderate fibrosis in MR, the agreement was moderate between imaging techniques and histology (kappa $=0.41)$. If this patient was kept in the comparison, the obtained agreement was poor $(\mathrm{kappa}=0.10)$.

There was no agreement (kappa $<0)$ between histomorphometric classification of fibrosis and the subjective histological classification.

No correlation was observed between spleen size or upper digestive bleeding and the intensity of LF.

\section{DISCUSSION}

Histology and MR confirmed Symmers' fibrosis in all cases; US failed to identify one patient. Imaging techniques presented moderate agreement with histology to rank LF. Histomorphometry did not agree with the histological classification of fibrosis. We also observed two patients with advanced hepatosplenic schistosomiasis with light LF.

Surgical wedge liver biopsy is considered the goldstandard procedure for diagnosing Symmers' fibrosis. In our study, MR identified LF with the same precision as histology. A marked divergence, though, occurred during classification of fibrosis intensity. Other studies using MR contained case reports or series of cases and they did not include liver biopsy to confirm the diagnosis and intensity of Symmers' fibrosis. However, using US, Homeida et al. (1988b) found results comparable to ours: the diagnosis of LF by US coincided with histology, but they presented poor agreement on fibrosis intensity.

Other studies used US to diagnosis the presence and grade the intensity of LF, but liver biopsy was only employed to confirm Symmers' fibrosis and to exclude other liver diseases (Abdel-Wahab et al. 1978, 1989, 1992, Cerri et al. 1984, Homeida et al. 1988a, Pinto-Silva et al. 1994).

In one of our patients, US failed to diagnosis LF. This deficiency has been previously described by Abdel-Wahab et al. (1989). Of their 18 patients with histological diagnosis of Symmers' fibrosis, two did not present US evidence of periportal thickening. It is also important to comment on one patient with sclerosing cholangitis excluded from our study: US images were indistinguishable from what is seen in patients with Symmers' fibrosis.

Needle liver biopsy frequently overlooks periportal fibrosis because it retrieves insufficient and fragmented tissue samples with a small number of portal tracts (Bogliolo 1957b). Taking this into consideration, our study was designed to obtain a surgical biopsy of the liver during splenectomy. Some authors criticise the wedge liver biopsy because fragments come from the periphery of the organ and fibrosis is not expected to be uniformly distributed (Brandt et al. 2002). Nevertheless, Dusek et al. (1965) states that a large enough specimen for histological assessment is obtainable only by surgical wedge biopsy and that the specimens are often sufficient to make an accurate diagnosis. In our opinion, the fragments obtained in our study $\left(\sim 3 \mathrm{~cm}^{3}\right)$ were large enough to permit a definitive diagnosis of Symmers' fibrosis.

Abdel-Wahab et al. (1992) and Richter et al. (1992) found that increases in portal and splenic vein diameters were significantly correlated with the degree of hepatic periportal fibrosis and the frequency of bleeding from endoscopically proven oesophageal varices. Here, we found no correlation between spleen size or a history of oesophageal bleeding and LF intensity. Interestingly, Andrade and Bina (1983), describing an autopsy series of 232 cadavers, stated that they found no correlation between the intensity of LF and evidence of portal hypertension and that, in fact, the latter resulted from intra-hepatic vessel obstruction rather than from LF (Prata \& Andrade 1963).

Histomorphometry is a method used to measure LF as a percentage of the hepatic tissue. No correlation between histological findings and morphometric measurements was observed in the present investigation. The reason for this is not clear, but a few points may be noted: (i) the usual histological examination by a pathologist is subjective and therefore difficult to evaluate (for exam- 

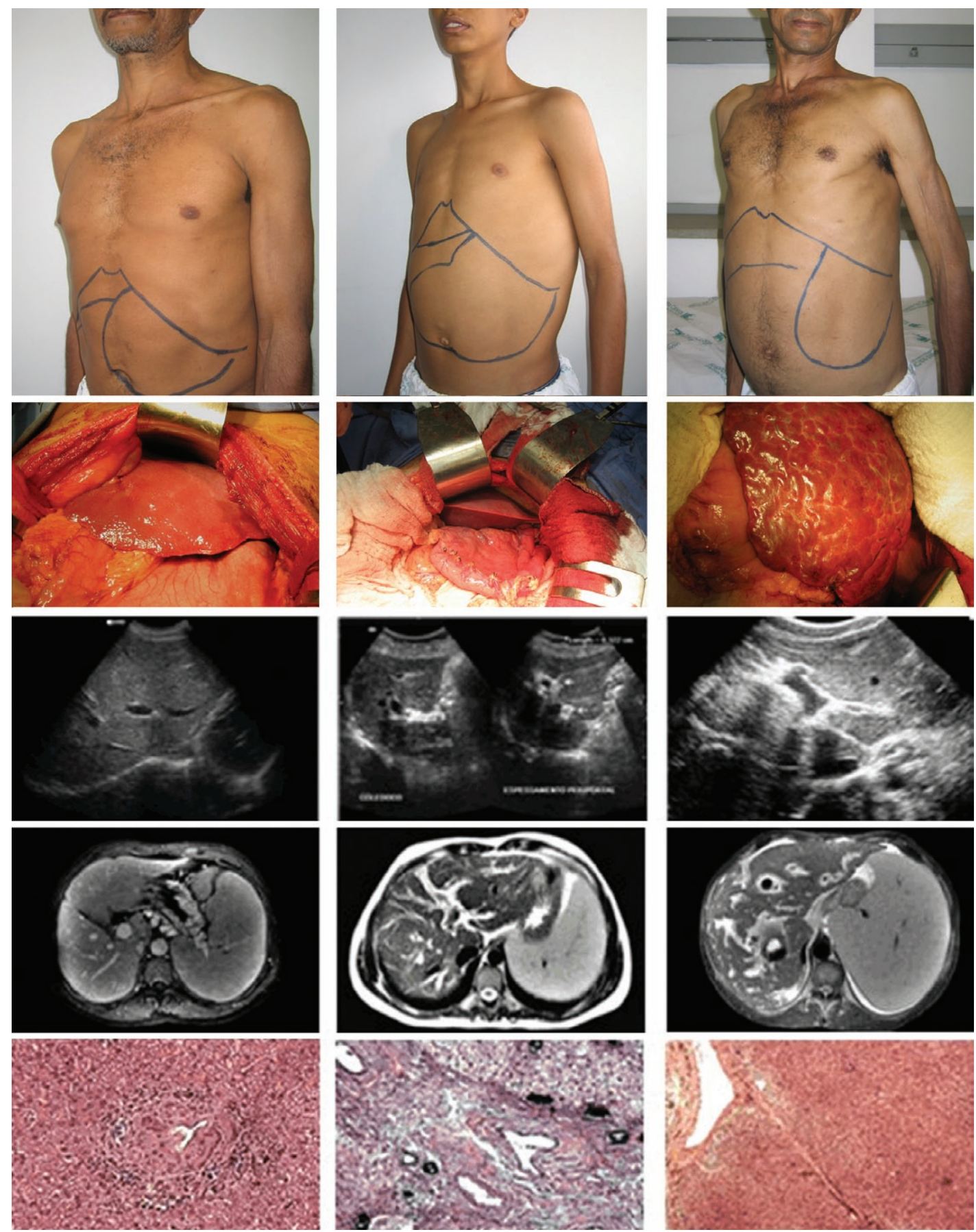

Fig. 6: clinical aspect of patients in the first row; surface of the liver in the second; ultrasound (US) in the third; magnetic resonance (MR) in the fourth and histology in the fifth. On the left column is the case of a patient with severe hepatosplenic schistosomiasis, but with a nearly normal liver, US without fibrosis, MR with light fibrosis and histology with moderate. In the middle column there is an example of moderate fibrosis and of intense fibrosis on the right.

ple, the classification of the intensity of fibrosis in hepatitis $\mathrm{C}$ is also subjective and a significant error among different examiners has been reported) (de Paula Farah et al. 2007) and (ii) LF is not homogeneously dispersed in the liver and even in the same fragment, fibrosis may be unevenly distributed. The same results have been described by others (Domingues 1998, Brandt et al. 2002).
Computed tomography (CT) has been used in schistosomiasis mansoni, revealing the presence of hypodense areas in the portal tracts, enhanced after contrast injection (Patel et al. 1993, Willemsen et al. 1995). Similar tomographic aspects have been reported for other diseases, such as Kaposi's sarcoma, sarcoidosis and liver alterations post-chemotherapy. To our 
TABLE II

Liver fibrosis and spleen size of 14 patients with advanced hepatosplenic schistosomiasis evaluated by physical examination, ultrasound (US), magnetic resonance (MR) and histology, Belo Horizonte, Minas Gerais, Brazil 2006-2007

\begin{tabular}{|c|c|c|c|c|c|c|c|c|}
\hline \multirow[b]{2}{*}{ Subject } & \multicolumn{5}{|c|}{ Liver fibrosis } & \multicolumn{3}{|c|}{ Spleen } \\
\hline & US & $\begin{array}{l}\text { WHO } \\
\text { pattern }\end{array}$ & MR & $\begin{array}{l}\text { WHO } \\
\text { pattern }\end{array}$ & Histology & $\begin{array}{l}\text { Physical examination } \\
\qquad(\mathrm{mm})\end{array}$ & $\begin{array}{l}\mathrm{US} \\
(\mathrm{mm})\end{array}$ & $\begin{array}{l}\mathrm{MR} \\
(\mathrm{mm})\end{array}$ \\
\hline 1 & $\mathrm{M}$ & $\mathrm{Ec}$ & $\mathrm{M}$ & $\mathrm{Ec}$ & I & 60 & 180 & 180 \\
\hline 2 & $\mathrm{M}$ & $\mathrm{Ec}$ & I & $\mathrm{Ec}$ & M & 80 & 202 & 194 \\
\hline 3 & $\mathrm{M}$ & $\mathrm{Ec}$ & $\mathrm{M}$ & Dc & M & - & 201 & 170 \\
\hline 4 & $\mathrm{M}$ & $\mathrm{Ec}$ & $\mathrm{M}$ & Dc & M & 100 & 202 & 210 \\
\hline 5 & $\mathrm{M}$ & $\mathrm{Ec}$ & $\mathrm{M}$ & $\mathrm{Ec}$ & $\mathrm{L}$ & 50 & 202 & 236 \\
\hline 6 & $\mathrm{M}$ & $\mathrm{Ec}$ & $\mathrm{M}$ & $\mathrm{F}$ & M & 80 & 200 & 181 \\
\hline 7 & $\mathrm{~L}$ & $\mathrm{D}$ & $\mathrm{M}$ & $\mathrm{Ec}$ & I & 70 & 178 & 190 \\
\hline 8 & $\mathrm{~A}$ & A & $\mathrm{L}$ & $\mathrm{D}$ & $\mathrm{M}$ & 140 & 230 & 220 \\
\hline 9 & I & $\mathrm{Ec}$ & $\mathrm{M}$ & $\mathrm{Dc}$ & I & 150 & 262 & 253 \\
\hline 10 & $\mathrm{M}$ & $\mathrm{Ec}$ & I & $\mathrm{F}$ & M & 120 & 216 & 250 \\
\hline 11 & $\mathrm{M}$ & $\mathrm{Ec}$ & $\mathrm{M}$ & $\mathrm{F}$ & I & $*$ & $*$ & $*$ \\
\hline 12 & $\mathrm{M}$ & $\mathrm{Ec}$ & I & $\mathrm{Ec}$ & I & $*$ & $*$ & $*$ \\
\hline 13 & $\mathrm{M}$ & $\mathrm{Ec}$ & I & $\mathrm{F}$ & $\mathrm{L}$ & 190 & 200 & 290 \\
\hline 14 & $\mathrm{M}$ & $\mathrm{E}$ & $\mathrm{M}$ & $\mathrm{E}$ & $\mathrm{M}$ & 60 & 213 & 200 \\
\hline
\end{tabular}

World Health Organization (WHO) patterns: A: absent; I: intense (F); L: slight (B, C, D, Dc); M: moderate (E, Ec) (Fig.2). Asterisk means splenectomized.

knowledge, there are no studies using positron emission tomography CT in hepatosplenic schistosomiasis. Non-invasive markers have also been used to predict the presence and degree of LF in hepatic diseases such as hepatitis $\mathrm{C}$, cirrhosis and schistosomiasis (Stone 2000, Guangjin et al. 2002, Afdhal \& Nunes 2004, Grigorescu 2006).

It is worth mentioning that MR reproduces the pathological findings of Symmers' fibrosis more clearly than US does and is naturally less invasive and timeconsuming than histology. The MR images are similar to those described by a pathologist when the liver is transversally cut during autopsy. Also, its superiority in the identification of portal vessels, portal vein thrombosis and collaterals should not be neglected (Bezerra et al. 2007). This information may help physicians plan in advance the surgical procedure that best suits their patients. On the other hand, MR is expensive. Due to its clear advantages, however, we believe it will be used more frequently in the near future.

Patients with hepatosplenic schistosomiasis in need of surgical intervention are those with severe portal hypertension, oesophago-gastric varices and hypersplenism (thrombocytopaenia, leukopenia and anaemia) (Petroianu 1983, 2003). It has been assumed that such patients would accordingly have intense periportal fibrosis, but here, we observed two patients with slight fibrosis diagnosed by histology presenting the severest clinical form of hepatosplenic schistosomiasis (huge spleens and massive variceal bleeding). Therefore, portal hypertension was probably caused by intrahepatic sinusoidal obstruction rather than periportal fibrosis.

In summary, LF intensity is not a definite surrogate marker of morbidity. Our data suggest that the intensity of LF evaluated by imaging techniques or histology does not relate to the severity of portal hypertension. The characteristic periportal fibrosis (diagnosed by US, MR or histology) associated with evidence of portal hypertension (large spleen, oesophageal varices and collateral vessels) should be sufficient to define disease severity and indicate surgical intervention, as necessary. We conclude that imaging techniques are reliable to define the presence of LF but fail in grading its intensity.

\section{REFERENCES}

Abdel-Latif Z, Abdel-Wahab MF, El-Kady NM 1981. Evaluation of portal hypertension in cases of hepatosplenic schistosomiasis using ultrasound. J Clin Ultrasound 9: 409-412.

Abdel-Wahab MF, Abdel-Latif Z, El-Kady NM, Arafa NM 1978. The use of ultrasonography in diagnosis of different schistosomalsyndromes. Proceedings of the Third International Workshop on Diagnostic Ultrasound Imaging (Cairo, Egypt), Al-Ahram Press, Cairo, p. 458-463.

Abdel-Wahab MF, Esmat G, Farrag A, el-Boraey Y, Strickland GT 1993. Ultrasonographic prediction of esophageal varices in schistosomiasis mansoni. Am J Gastroenterol 88: 560-563.

Abdel-Wahab MF, Esmat G, Farrag A, el-Boraey YA, Strickland GT 1992. Grading of hepatic schistosomiasis by the use of ultrasonography. Am J Trop Med Hyg 46: 403-408.

Abdel-Wahab MF, Esmat G, Milad M, Abdel-Razek S, Strickland GT 
1989. Characteristic sonographic pattern of schistosomal hepatic fibrosis. Am J Trop Med Hyg 40: 72-76.

Afdhal NH, Nunes D 2004. Evaluation of liver fibrosis: a concise review. Am J Gastroenterol 99: 1160-1174.

Andrade ZA 2004. Schistosomal hepatopathy. Mem Inst Oswaldo Cruz 99 (Suppl. I): 51-57.

Andrade ZA 2005. Regression of hepatic fibrosis. Rev Soc Bras Med Trop 38: 514-520.

Andrade ZA, Bina JC 1983. A patologia da forma hepato-esplênica da esquistossomose mansoni em sua forma avançada (estudo de 232 necrópsias completas). Mem Inst Oswaldo Cruz 78: 285-305.

Barbosa Jr AA 2001. Morphological computer-assisted quantitative estimation of stained fibrous tissue in liver sections: applications in diagnosis and experimental research. $J$ Bras Patol 37: 197-200.

Bezerra AS, D'Ippolito G, Caldana RP, Cecin AO, Ahmed M, Szejnfeld J 2007. Chronic hepatosplenic schistosomiasis mansoni: magnetic resonance imaging and magnetic resonance angiography findings. Acta Radiol 48: 125-134.

Bogliolo L 1957a. A esplenoportografia da esquistossomose mansônica hepatoesplênica, forma de Symmers. Rev Assoc Med Bras 3: $263-269$

Bogliolo L 1957b. Anatomical picture of the liver in hepatosplenic schistosomiasis mansoni. Ann Trop Med Parasitol 51: 1-14.

Brandt CT, Domingues ALC, Vilela P, Sena A, Marques K, Giusti CF 2002. Histomorphometry of hepatic portal fibrosis in patients with surgical schistosomiasis mansoni. Acta Cir Bras 17 (Suppl. 1): 7-10.

Cairo Working Group 1992. The use of diagnostic ultrasound in schistosomiasis - attempts at standardization of methodology. Acta Trop 51: 45-63.

Cerri GG, Alves VA, Magalhães A 1984. Hepatosplenic schistosomiasis mansoni: ultrasound manifestations. Radiology 153: 777-780.

Coutinho EM, Barros AF, Barbosa A Jr, Oliveira SA, Silva LM, Araújo RE, Andrade ZA 2003. Host nutritional status as a contributory factor to the remodeling of schistosomal hepatic fibrosis. Mem Inst Oswaldo Cruz 98: 919-925.

Davidson RN, Houston S, Kiire CF 1991. Schistosomal periportal fibrosis in Zimbabwe: use of ultrasound in patients with oesophageal varices. Trans $R$ Soc Trop Med Hyg 85: 380-382.

Doehring-Schwerdtfeger E, Abdel-Rahim IM, Kardorff R, Kaiser C, Franke D, Schlake J, Richter J, Elsheikh M, Mohamed-Ali Q, Ehrich JHH 1992. Ultrasonographical investigation of periportal fibrosis in children with Schistosoma mansoni infection: reversibility of morbidity twenty-three months after treatment with praziquantel. Am J Trop Med Hyg 46: 409-415.

Domingues ALC 1998. Ultra-sonografia na esquistossomose mansônica hepato-esplênica: avaliação da intensidade da fibrose periportal e da hipertensão porta, $\mathrm{PhD}$ Thesis, Universidade $\mathrm{Fe}-$ deral de Pernambuco, Recife, 99 pp.

Dusek J, Kubasta M, Kodousek R, Kubastova B 1965. Needle biopsy of the liver in shistosomiasis mansoni: the value of histological examination. J Trop Med Hyg 68: 189-195.

Grigorescu M 2006. Noninvasive biochemical markers of liver fibrosis. J Gastrointestin Liver Dis 15: 149-159.

Guangjin S, Mingdao J, Qiyang L, Hui X, Jiangming H, Xiaomei Y 2002. Study on histopathology, ultrasonography and some special serum enzymes and collagens from 38 advanced patients of schistosomiasis japonica. Acta Trop 82: 235-246.
Homeida M, Abdel-Gadir AF, Cheever AW, Bennett JL, Arbab BM, Ibrahium SZ, Abdel-Salam IM, Dafalla AA, Nash TE 1988a. Diagnosis of pathologically confirmed Symmers' periportal fibrosis by ultrasonography: a prospective blinded study. Am J Trop Med Hyg 38: 86-91.

Homeida M, Ahmed S, Dafalla A, Suliman S, Eltom I, Nash T, Bennett JL 1988b. Morbidity associated with Schistosoma mansoni infection as determined by ultrasound: a study in Gezira, Sudan. $\mathrm{Am}$ J Trop Med Hyg 39: 196-201.

Lambertucci JR 1993. Schistosoma mansoni: pathological and clinical aspects. In P Jordan, G Webbe (eds.), Human schistosomiasis, Cab International, Wallingford, p. 195-225.

Lambertucci JR, Andrade LM, Pinto-Silva RA 2002. Magnetic resonance imaging of the liver in hepatosplenic schistosomiasis mansoni. Rev Soc Bras Med Trop 35: 679-680.

Lambertucci JR, Cota GF, Pinto-Silva RA, Serufo JC, GerspacherLara R, Drummond SC, Antunes CM, Nobre V, Rayes A 2001. Hepatosplenic schistosomiasis in field-based studies: a combined clinical and sonographic definition. Mem Inst Oswaldo Cruz 96 (Suppl.): $147-150$.

Lambertucci JR, dos Santos Silva LC, Andrade LM, de Queiroz LC, Carvalho VT, Voieta I, Antunes CM 2008. Imaging techniques in the evaluation of morbidity in schistosomiasis mansoni. Acta Trop 108: 209-217.

Lambertucci JR, Serufo JC, Gerspacher-Lara R, Rayes AA, Teixeira $\mathrm{R}$, Nobre V, Antunes CM 2000. Schistosoma mansoni: assessment of morbidity before and after control. Acta Trop 77: 101-109.

Lambertucci JR, Silva LC, Andrade LM, de Queiroz LC, PintoSilva RA 2004. Magnetic resonance imaging and ultrasound in hepatosplenic schistosomiasis mansoni. Rev Soc Bras Med Trop 37: 333-337.

Landis JR, Koch GG 1977. The measurement of observer agreement for categorical data. Biometrics 33: 159-174.

Maia MD, Lopes EP, Ferraz AA, Barros FM, Domingues AL, Ferraz EM 2007. Evaluation of splenomegaly in the hepatosplenic form of mansonic schistosomiasis. Acta Trop 101: 183-186.

Marinho CC, Voieta I, Azeredo LM, Nishi MP, Batista TS, Pereira ACF, Serufo JC, de Queiroz LC, Ruiz-Guevara R, Antunes CM, Prata A, Lambertucci JR 2006. Clinical versus ultrasound examination in the evaluation of hepatosplenic schistosomiasis mansoni in endemic areas. Mem Inst Oswaldo Cruz 101 (Suppl. I): 317-321.

Niamey Working Group 1996. Ultrasound in schistosomiasis. A practical guide to the standardized use of ultrasonography for the assessment of schistosomiasis-related morbidity. UNDP/ World Bank/WHO/Special Programme for Research \& Training in Tropical Diseases (TDR). World Health Organization/TDR/ SCH/ULTRASON document, Geneva. Available from: http:// apps.who.int/tdr/svc/publications/training-guideline-publications/ultrasound-in-schistosomiasis.

Patel SA, Castillo DF, Hibbeln JF, Watkins JL 1993. Magnetic resonance imaging appearance of hepatic schistosomiasis, with ultrasound and computed tomography correlation. Am J Gastroenterol 88: 113-116.

Petroianu A 1983. A esplenectomia subtotal e anastomose esplenorrenal proximal para o tratamento da hipertensão portal. Rev Bras Cir 73: 101-104.

Petroianu A 2003. Tratamento cirúrgico da hipertensão porta da esquistossomose mansoni. Rev Soc Bras Med Trop 36: 253-265.

Pinto-Silva RA, Abrantes WL, Antunes CM, Lambertucci JR 1994. Sonographic features of portal hypertension in schistosomiasis mansoni. Rev Inst Med Trop Sao Paulo 36: 355-361. 
Prata A 1987. Schistosomiasis mansoni in Brazil. Baillieres Clin Trop Med Comm Dis 2: 349-369.

Prata A, Andrade ZA 1963. Fibrose hepática de Symmers sem esplenomegalia. Hospital (Rio J) 63: 617-623.

Richter J, Correia Dacal AR, Vergetti Siqueira JG, Poggensee G, Mannsmann U, Deelder A, Feldemeier H 1998. Sonographic prediction of variceal bleeding in patients with liver fibrosis due to Schistosoma mansoni. Trop Med Int Health 3: 728-735.

Richter J, Zwingenberger K, Ali QM, Lima W de M, Dacal AR, de Siqueira GV, Doehring-Schwerdtfeger E, Feldmeier H 1992. Hepatosplenic schistosomiasis: comparison of sonographic findings in Brazilian an Sudanese patients - correlation of sonographic findings with clinical symptoms. Radiology 184: 711-716.
Silva LC 2007. Comparação entre a ultra-sonografia e a ressonância magnética do abdome na avaliação da morbidade na esquistossomose mansônica, PhD Thesis, Universidade Federal de Minas Gerais, Belo Horizonte, $97 \mathrm{pp}$.

Silva LC, Pereira AC, Queiroz LC, Andrade LM, Antunes CM, Lambertucci JR 2006. Disagreement between ultrasound and magnetic resonance imaging in the identification of schistosomal periportal fibrosis. Mem Inst Oswaldo Cruz 101 (Suppl. I): 279-282.

Stone PJ 2000. Potential use of collagen and elastin degradation markers for monitoring liver fibrosis in schistosomiasis. Acta Trop 77: 97-99.

Willemsen UF, Pfluger T, Zoller WG, Kueffer G, Hahn K 1995. MRI of hepatic schistosomiasis mansoni. J Comput Assit Tomogr 19: 811-813. 